\title{
Comparison of Efficacy and Safety Evaluation of Latanoprost Formulations with and without Benzalkonium Chloride
}

\author{
Hiroyoshi Kasai $^{1 *}$, Yumiko Aoyama ${ }^{2}$, Takashi Kurasawa ${ }^{3}$, Tomoyo Imamura ${ }^{4}$, Kazuhiro Tsuruma ${ }^{4}$, \\ Hideaki Hara $^{4}$, Haruhisa Hirata ${ }^{3}$, Tetsuya Yamamoto ${ }^{2}$ \\ ${ }^{1}$ Research and Development, Wakamoto Pharmaceutical Co., Ltd., Tokyo, Japan; ${ }^{2}$ Department of Ophthalmology, Gifu University \\ Graduate School of Medicine, Gifu, Japan; ${ }^{3}$ Sagami Research Laboratories, Wakamoto Pharmaceutical Co., Ltd., Kanagawa, Japan; \\ ${ }^{4}$ Molecular Pharmacology, Department of Biofunctional Evaluation, Gifu Pharmaceutical University, Gifu, Japan. \\ Email: "kasai@wakamoto-pharm.co.jp
}

Received April 21 $1^{\text {st }}, 2013$; revised June $2^{\text {nd }}, 2013$; accepted June $12^{\text {th }}, 2013$

Copyright (C) 2013 Hiroyoshi Kasai et al. This is an open access article distributed under the Creative Commons Attribution License, which permits unrestricted use, distribution, and reproduction in any medium, provided the original work is properly cited.

\begin{abstract}
Background: This study investigated the safety (cytotoxicity in vitro) and pharmacological effects (ocular hypotensive effects and aqueous humor concentrations in normotensive monkeys in vivo) of latanoprost formulations with benzalkonium chloride (latanoprost with BAK) and without BAK (NP). Methods: A bioequivalence study of latanoprost with BAK and NP was also conducted on human healthy volunteers. Cytotoxicity and the protective effect against $\mathrm{H}_{2} \mathrm{O}_{2}$ stress in vitro were evaluated using human corneal epithelial cells. The ocular hypotensive effects in normotensive monkeys were measured by pneumatonometer and the aqueous humor concentrations of latanoprost free acid were determined by liquid chromatography/mass spectrum (LC/MS) methods. The bioequivalence study of latanoprost with BAK and NP was carried out as a single eye drop, two-sequence, crossover randomized study. Results: Cytotoxicity tests in vitro revealed that NP was less toxic than latanoprost with BAK and significantly inhibited $\mathrm{H}_{2} \mathrm{O}_{2}$ induced cell damage while latanoprost with BAK did not. The hypotensive efficacy and the latanoprost free acid concentrations in aqueous humor of each formulation were not significantly different in monkeys. In the bioequivalence study, NP was bioequivalent to latanoprost with BAK. NP was safer than latanoprost with BAK with respect the results obtained in the in vitro cytotoxicity test. There was no difference observed between latanoprost with BAK and NP in the IOP lowering effect in monkeys and healthy volunteers. Conclusion: Taken together, these results indicate that NP is as effective as latanoprost with BAK, and is more likely to maintain ocular surface health than latanoprost with BAK.
\end{abstract}

Keywords: Latanoprost; NP; Benzalkonium; Benzalkonium-Free; Bioequivalence

\section{Introduction}

The most common type of glaucoma is primary open angle glaucoma (POAG) and is characteristic of higher intraocular pressure (IOP) induced by various factors. Though high IOP is one of the most important risk factors for glaucoma, an epidemiological glaucoma survey has demonstrated that the prevalence of normal tension glaucoma (NTG) is 3.6\% and revealed NTG is one of the most common types of glaucoma in Japan, with more than $90 \%$ of POAG cases diagnosed as NTG over the past 40 years [1].

Prostaglandin analogs are widely used to treat patients

${ }^{*}$ Corresponding author. with glaucoma by reducing IOP. Among prostaglandin analogs, latanoprost is the first commercially available prostaglandin $\mathrm{F}_{2 \alpha}$ analogue and is the first choice as a therapy to manage patients as it markedly reduces IOP with administration just once a day [2,3]. A long-term latanoprost monotherapy study on Japanese glaucoma patients with NTG and POAG has indicated that latanoprost monotherapy achieves stable IOP reduction and maintenance of the visual field [4].

Glaucoma patients are treated with eye drops for their entire life and, as a result, they frequently suffer ocular surface problems $[5,6]$. In a multicenter cross-sectional epidemiologic survey in four European countries that examined the difference in side effects between ophthal- 
mic solutions with preservatives and solutions without preservatives which are contained in multi-dose packaging to prevent microbial and fungal contamination, the results in each facility indicated that ocular symptoms and signs, such as pain, discomfort, dry eye sensation, burning, eyelid itching, anterior or posterior blepharitis, hyperemia and fluorescein staining were significantly decreased in patients taking preservative free eye drops compared with those who received preserved ophthalmic solutions [7]. The most widely used preservative is benzalkonium chloride (BAK), which is contained in latanoprost. Many studies, including in vitro and in vivo studies, have demonstrated that BAK may cause or accelerate harmful events to the ocular tissues such as the ocular tear film, cornea, conjunctiva, the anterior segment, trabecular meshwork, and even the retina [8-13].

Recently, lots of generic formulations for the commercially available latanoprost were approved and launched in Japan, but almost all of them include BAK as a preservative. The purpose of this study is to compare the pharmacological and toxicological profile of latanoprost ophthalmic solution $0.005 \%\lceil\mathrm{NP}\rfloor(\mathrm{NP})$, which is one of the generic drugs for latanoprost without BAK, with latanoprost containing $0.02 \%$ BAK manufactured by Pfizer, Inc. and known by the brand name "Xalatan".

\section{Materials and Methods}

\subsection{Materials}

A commercially available latanoprost ophthalmic formulation containing $0.02 \%$ BAK (Xalatan) was purchased from Pfizer Inc. (New York, NY). Latanoprost ophthalmic solution $0.005 \%\lceil\mathrm{NP}\rfloor$ (Nipro Pharma Corporation, Japan) was used as the latanoprost ophthalmic solution without BAK. BAK was obtained from Tokyo Chemical Industry Co., Ltd. (Tokyo, Japan) or MP Biomedicals, Inc. (California, USA) Trolox (Enzo Life Science, Inc., USA), a water-soluble derivative of $\alpha$-tocopherol, was used as an antioxidant.

\subsection{Animals}

Ten male cynomolgus monkeys aged 4 years or above were used in this experiment. This study was conducted by contact research laboratory which is accredited by the Association for Assessment and Accreditation of Laboratory Animal Care International (AAALAC International). All procedures conformed to the Association for Research in Vision and Ophthalmology Statement for the Use of Animals in Ophthalmic and Vision Research and the guidelines for animal care produced by Wakamoto Pharmaceutical Co., Ltd. The animals were housed in a $12 \mathrm{~h}$ light-dark cycle (light-on was defined as 7:00 am, and light-off occurred at 7:00 pm).

\subsection{Subjects}

Twelve healthy Japanese male volunteers aged between 20 - 24 years old were enrolled in the study. The study protocol conformed to the ethical guidelines of the Declaration of Helsinki as reflected by the approval from the institutional review board of Wakamoto Pharmaceutical Co., Ltd. The purpose of this study and the protocols was explained to all subjects, and their prior written informed consent was obtained. Subjects were deemed to be in good health on the basis of their medical history, a physical examination, routine blood test and ophthalmological examination.

\subsection{Cytotoxicity Test of Latanoprost with BAK and NP in Vitro}

SV-40 transformed human corneal epithelial cells (HCECs; RIKEN BioResource Center, Japan; RCB No. 2280) were used in this study. HCECs were cultured at $37^{\circ} \mathrm{C}$ and $5 \% \mathrm{CO}_{2}$ for $24 \mathrm{~h}$ to confluence in supplemental hormonal epithelial medium (SHEM), which is made of an equal volume of DMEM and Ham's F12 containing $0.5 \%$ dimethyl sulfoxide, $5 \mu \mathrm{g} / \mathrm{mL}$ insulin, $2.75 \mu \mathrm{g} / \mathrm{mL}$ transferrin, $3.35 \mathrm{ng} / \mathrm{mL}$ selenium, $10 \mathrm{ng} / \mathrm{mL}$ recombinant human epidermal growth factor (EGF) and 5\% fetal bovine serum (FBS), and the cells were exposed to latanoprost with BAK, NP or $0.02 \%$ BAK for $1,2,5$ and 10 mins. After exposure to latanoprost with BAK, NP or $0.02 \% \mathrm{BAK}$, the medium was removed and HCECs were incubated with SHEM. $24 \mathrm{~h}$ after incubation, cell viability was determined by WST-8 assay system, a colorimetric assay for the quantification of cell viability based on the cleavage of the tetrazolium salt WST- 8 by mitochondrial dehydrogenases in viable cells. The cells were incubated with $100 \mu \mathrm{L}$ of WST-8 (10 $\mu \mathrm{L}$ in $90 \mu \mathrm{L}$ media) for $2 \mathrm{~h}$ and absorbance was measured at $450 \mathrm{~nm}$ (with the reference wavelength at $630 \mathrm{~nm}$ ). HCECs were seeded into 96-well plates at a density 6000 cells per well at $37^{\circ} \mathrm{C}$ and $5 \% \mathrm{CO}_{2}$ for $24 \mathrm{~h}$ in SHEM. Then, these were exposed to latanoprost with BAK and NP $(1 / 100,1 / 300$, 1/500, 1/1000 diluted with SHEM) or $0.02 \%$ BAK for 12 $\mathrm{h}$ and incubated to determine the nontoxic concentration. After incubation, cell viability was determined by WST8 assay.

\subsection{Pharmacological Test of Latanoprost with BAK and NP in Vitro}

HCECs were seeded and incubated as above-maintained for $24 \mathrm{~h}$. After incubation, latanoprost with BAK, NP, $0.02 \%$ BAK, $0.000066 \%$ BAK (a quantity of BAK equal to latanoprost with $0.02 \%$ BAK diluted at $1 / 300$ ) or Trolox were pretreated for $1 \mathrm{~h}$, and $\mathrm{H}_{2} \mathrm{O}_{2}$ (at a final concentration of $0.3 \mathrm{mM}$ ) was added. $12 \mathrm{~h}$ after $\mathrm{H}_{2} \mathrm{O}_{2}$ treat- 
Formulations with and without Benzalkonium Chloride

ment, the medium was removed and cell viability was determined by the WST-8 assay.

\subsection{Efficacy and Safety of Latanoprost with BAK and NP Repeated Instillation and Latanoprost Free Acid Concentrations in Aqueous Humor in Normotensive Cynomolgus Monkeys}

All procedures were conducted in accordance with Act on Welfare and Management of Animals and approved by the Institutional Animal Care and Use Committee of Ina Research incorporation (Nagano, Japan). Male cynomolgus monkeys trained to the point where they could be handled under monkey chair with arms free, without general anesthesia, were used in the IOP measurement experiment. IOP measurement was performed by pneumatonometer (Model $30^{\mathrm{TM}}$ pneumatonometer, Reichert Technologies, USA) and $20 \mu \mathrm{L}$ of latanoprost with BAK or NP was instilled into the middle of the lower conjunctival sac of the left eye, whereas the right eye was not treated. Instillations were repeated once daily for 8 weeks. The IOP was measured before first instilllation and 2, 4, 6 and $24 \mathrm{~h}$ after instillation on Day 1, Day 8, Day 15, Day 29 and Day 57. Clinical signs were observed every day and corneal damage was examined according to Modified McDonald-Shadduck scoring methods [14] before first instillation and on Day 3, Day 28 and Day 56.

The animals were intramuscularly injected with 2.5 $\mathrm{mg} / \mathrm{kg}$ ketamine hydrochloride for general anesthesia and aqueous humor samples were taken $1 \mathrm{~h}$ after instillation at Day 58. The samples were frozen and stored at below $-60^{\circ} \mathrm{C}$ until they were assayed for latanoprost free acid concentrations by a liquid chromatography-mass spectrometry (LC/MS) method.

\subsection{Bioequivalence Study of Latanoprost with BAK and NP}

All procedures were conducted in accordance with the Helsinki Declaration. This study was approved by the Institutional Review Board of Osaka Pharmacology Clinical Research Hospital (Osaka, Japan). A bioequivalence study of latanoprost with BAK and NP was carried out on 12 healthy male Japanese volunteers as a single eye drop, double-blind, 2-period, 2-treatment, 2-sequence, and crossover randomized study. The two formulations were administered in both treatment days, separated by a washout period of 7 days. IOP was measured before instillations and 2, 4, 6, 8, 12, 14 and $24 \mathrm{~h}$ after treatment. Two pharmacokinetic parameters, namely, maximal reduction IOP $\left(\Delta \mathrm{C}_{\max 0-24 \mathrm{~h}}\right)$ and total area under the IOPtime curve $\left(\Delta \mathrm{AUC}_{0-24 \mathrm{~h}}\right)$, were obtained from IOP values versus time profiles. The Guideline for Bioequivalence Studies of Generic Products [15] in Japan was adapted for the acceptance criteria. The $90 \%$-confidence intervals (CIs) of difference in average value of logarithmic $\Delta \mathrm{AUC}_{0-24 \mathrm{~h}}$ and $\Delta \mathrm{C}_{\operatorname{max0}-24 \mathrm{~h}}$ values were used to assess bioequivalence. Bioequivalence was accepted if the calculated $90 \%$-CIs were within $80 \%-125 \%$.

\subsection{Statistical Analysis}

In vitro toxicological and pharmacological studies, each value was expressed as the mean \pm standard error of the mean. The differences between the control and each evaluation group were analyzed by 2 -tailed t-test. Dunnett's method was used for multiple comparisons with the control group. In the studies on efficacy, safety and the measurement of latanoprost free acid concentrations in normal cynomolgus monkeys, the results were presented as mean \pm standard deviation. Statistical analyses were performed using Student's t test, or Aspin-Welch's $t$ test, after one way analysis of variance (ANOVA) between results for latanoprost with BAK or NP at each time point. The level of significance was taken as $p<$ 0.05 and $p<0.01$ in all studies.

\section{Results}

\subsection{In Vitro Cytotoxicity Test of Latanoprost with BAK and NP}

In vitro cytotoxicity test of latanoprost with BAK and NP. The cytotoxicity after exposure to latanoprost with BAK, NP or $0.02 \%$ BAK for $1,2,5$ and 10 min on HCECs was shown in Figure 1(a). Cell viability after exposure to latanoprost with BAK and $0.02 \%$ BAK for 1 to $10 \mathrm{~min}$ was all $0 \%$. On the other hand, cell viability after exposure to NP for $1,2,5$ and 10 min was $106.2 \%, 87.1 \%$, $76.6 \%$ and $67.5 \%$, respectively. In addition, cytotoxicity of latanoprost with BAK and NP at low concentrations over a long period of time was examined in Figure 1(b). HCECs were incubated for $12 \mathrm{~h}$ in SHEM which contained latanoprost with BAK and NP at the concentration of $1 / 100,1 / 300,1 / 500,1 / 1000$ or $0.02 \%$ BAK. Cytotoxicity of SHEM as the control was not observed. Treatment with 100-fold-diluted latanoprost with BAK or $0.02 \%$ BAK significantly reduced the cell viability, but treatment with NP did not reduce cell viability.

\subsection{In Vitro Pharmacological Test of Latanoprost with BAK and NP}

In vitro pharmacological test of latanoprost with BAK and NP. The protective effect of latanoprost with BAK and NP on HCECs damage induced by oxidative stress is shown in Figure 2. Three hundred-fold-diluted latano- 


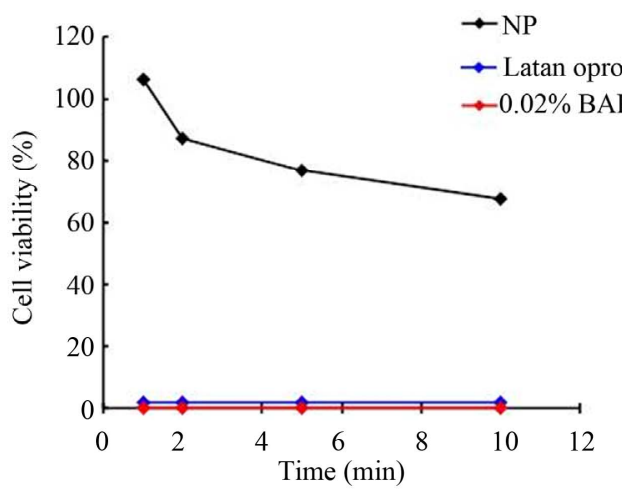

(a)

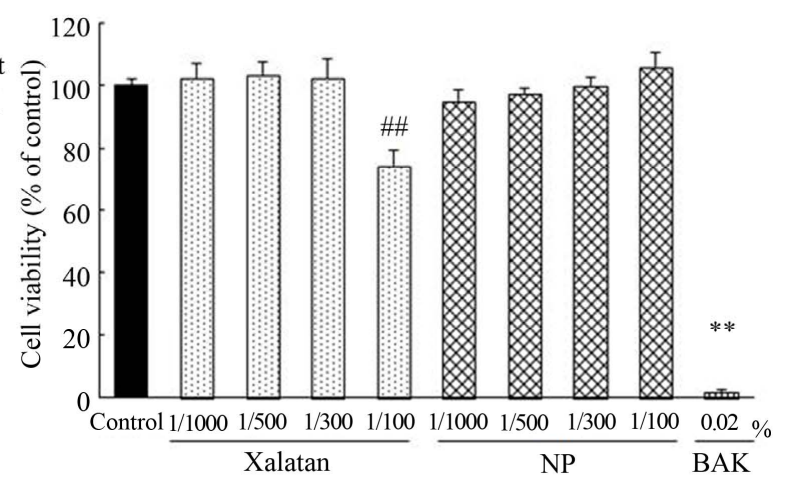

(b)

Figure 1. Cytotoxicity of latanoprost, $0.02 \%$ BAK and NP on HCECs. (a) HCECs were exposed for 1, 2, 5 and 10 min by each samples. Data represents the percentage of PBS-treated cell viability. Each value was expressed the mean (n = 12); (b) HCECs were exposed for $12 \mathrm{~h}$ by each agent. Data represents the percentage of SHEM-treated cell viability. Each value was expressed the mean \pm SEM $(n=6) .{ }^{\# \#} p 0.01$ versus control (Dunnet’s test). ${ }^{* *} p<0.01$ versus control ( $t$-test).

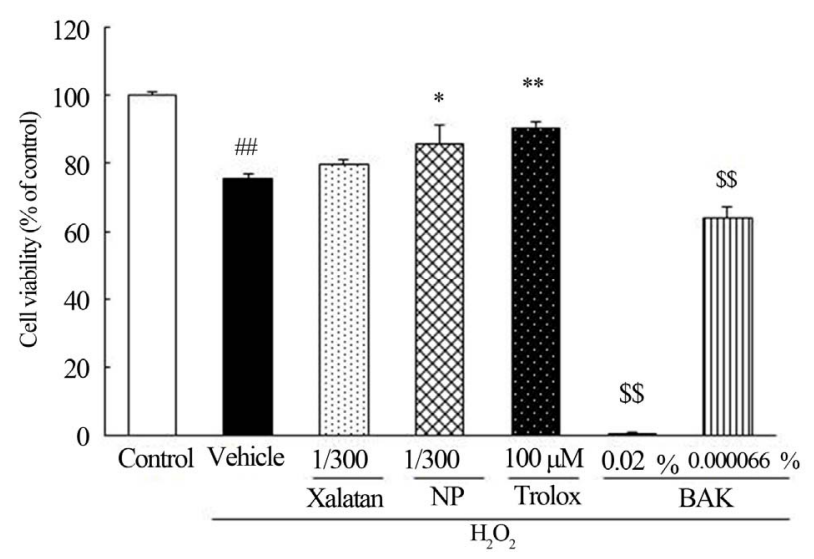

Figure 2. Effect of latanoprost, NP, BAK and Trolox on cell damage induced by $\mathrm{H}_{2} \mathrm{O}_{2}$ in HCECs. HCECs were damaged by $\mathrm{H}_{2} \mathrm{O}_{2}(0.3 \mathrm{mM})$. HCECs were pretreated 300 -fold-diluted latanoprost, NP, $0.02 \%, 0.000066 \%$ BAK, and Trolox. Data represents the percentage of PBS-treated cell viability. Each value was expressed the mean $\pm \operatorname{SEM}(n=6)$. ${ }^{\# p}<0.01$ versus control (t-test). ${ }^{*},{ }^{* *} p<0.05,0.01$ versus vehicle plus $\mathrm{H}_{2} \mathrm{O}_{2}$ treated group (t-test). ${ }^{\$ \$} \mathrm{p}<0.01$ versus control (Dunnet's test).

prost with BAK had no effect on HCECs damage induced by $\mathrm{H}_{2} \mathrm{O}_{2}$, whereas NP significantly inhibited the $\mathrm{H}_{2} \mathrm{O}_{2}$ induced cell damage. Not only $0.02 \%$ BAK, but $0.000066 \% \mathrm{BAK}$, equivalent to the concentration of BAK in 300-fold-diluted latanoprost with BAK, exacerbated oxidative stress-induced cell damage.

\subsection{Efficacy and Safety of Latanoprost with BAK and NP Repeated Instillation and Latanoprost Free Acid Concentrations in Aqueous Humor in Normotensive Cynomolgus Monkeys}

Efficacy and safety of latanoprost with BAK and NP repeated instillation and latanoprost free acid concentrations in aqueous humor in normal cynomolgus monkeys. Changes in IOP in normal male cynomolgus monkeys by repeated topical instillation once daily for 8 weeks of latanoprost with BAK and NP are shown in Figure 3. Mean IOP before instillation of latanoprost with BAK was $20.14 \pm 2.65 \mathrm{mmHg}$. IOP reduction by latanoprost with BAK reached maximum levels between 4 and $6 \mathrm{~h}$ after instillation, and the difference of measured IOP values before and after application of latanoprost with BAK was $1.74-2.60$ during the duration of instillation. Mean IOP before instillation of NP was $20.60 \pm 2.30$ $\mathrm{mmHg}$. IOP reduction by NP reached maximum levels between 4 and $6 \mathrm{~h}$ after administration similarly to the latanoprost with BAK results. The difference of measured IOP values before and after application of NP was $2.34-3.52 \mathrm{mmHg}$ during the duration of instillation. The maximal IOP reduction $(\Delta \mathrm{mmHg})$ of latanoprost with BAK and NP was $3.54 \pm 0.58$ and $4.12 \pm 0.94 \mathrm{mmHg}$, respectively. This study indicated that maintenance of IOP reduction was obtained with repeated administration of both latanoprost with BAK and NP, and that there was no difference in their effect. In observation of corneal epithelium damage, neither latanoprost with BAK nor NP showed symptoms of corneal staining. There were no differences in clinical observations including eyelid closure, corneal opacity, hyperemia of conjunctiva and iris, or pupillary condition between latanoprost with BAK and NP treated groups. Latanoprost free acid concentrations are shown in Table 1. The range of latanoprost free acid concentrations after treatment with latanoprost with BAK and NP was $13.33-39.96 \mathrm{ng} / \mathrm{mL}$ and $12.71-17.32$ $\mathrm{ng} / \mathrm{mL}$ respectively. There was no significant difference in latanoprost free acid concentrations after instillation of latanoprost with BAK and NP, although mean values tended to be higher in the latanoprost BAK group. 


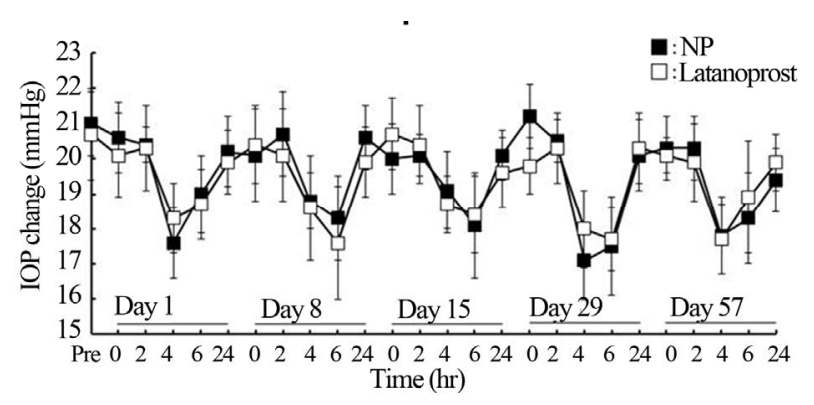

Figure 3. Time course of the change in intraocular pressure (IOP) of normotensive male cynomolgus monkeys after repeated instillation of latanoprost with or witout BAK. IOPlower effects of $\mathbf{0 . 0 0 5 \%}$ latanoprost with or without BAK ophthalmic solutions was followed for 8 weeks. Each point was expressed the mean \pm S.D. $(n=5)$. No significant difference was observed between the two eyes at any time point.

Table 1. Concentrations of latanoprost free acid in aqueous humor (ng/mL).

\begin{tabular}{ccc}
\hline Animal No. & Latanoprost & NP \\
\hline 1 & 39.96 & 12.71 \\
2 & 18.93 & 14.46 \\
3 & 38.37 & 17.32 \\
4 & 23.58 & 16.94 \\
5 & 13.33 & 14.88 \\
Ave. & 26.83 & 15.26 \\
SD & 11.84 & 1.89 \\
\hline
\end{tabular}

Individual values of concentration are indicated.

Bioequivalence study of latanoprost with BAK and NP Pharmacodynamics parameters are shown in Table 2. Maximal IOP reduction $\left(\Delta \mathrm{C}_{\max 0-24 \mathrm{~h}}\right)$ was $3.08 \pm 1.38$ $\mathrm{mmHg}$ for latanoprost with BAK and $3.25 \pm 1.06 \mathrm{mmHg}$ for NP. The $90 \%$-CIs of the ratio of the geometric means for log-transformed for $\Delta \mathrm{C}_{\max 0-24 \mathrm{~h}}$ of latanoprost with BAK and NP were $81.22 \%-116.85 \%$ and remained within the standard acceptance range of $80 \%-125 \%$. $\triangle \mathrm{AUC}_{0-24 \mathrm{~h}}$, which was determined from differences between IOP before instillations and IOP at each point, was $39.67 \pm 26.83 \mathrm{mmHg} \cdot \mathrm{hr}$ for latanoprost with BAK and $43.00 \pm 19.77 \mathrm{mmHg} \cdot \mathrm{hr}$ for NP. The $90 \%$-CIs of the ratio of the geometric means for log-transformed for $\triangle \mathrm{AUC}_{0-24 \mathrm{~h}}$ of latanoprost with BAK and NP were 91.60 $106.27 \%$ and remained within the standard acceptance range of $80 \%-125 \%$. Ocular adverse events related to the test formulations were not observed, and both treatments exhibited similar tolerability and safety on ocular surfaces. It was concluded that NP was bioequivalent to latanoprost with BAK. The template is used to format your paper and style the text. All margins, column widths, line spaces, and text fonts are prescribed; please do not alter them. You may note peculiarities. For example, the head margin in this template measures proportionately more than is customary. This measurement and others are deliberate, using specifications that anticipate your paper as one part of the entire proceedings, and not as an independent document. Please do not revise any of the current designations.

\section{Discussion}

According to the investigation of the trend of IOP control and anti-glaucoma ophthalmic solutions from 2000 through 2008 in Japan, prostaglandin analogues were the most frequently prescribed anti-glaucoma ophthalmic solutions, accounting for $40 \%$ to $45 \%$ of prescriptions [16]. Among the PG analogues, latanoprost is a first-line prostaglandin analog formulation for patients with glaucoma to control IOP, and exhibits potent pharmacological activity with one daily application [2,3,17-21].

Commercially available latanoprost (Xalatan) is a multidose type formulation so it needs to contain an antimicrobial preservative, BAK. In recent years, as increasing attention has been paid to various ocular surface disorders, such as dry eye disease, conjunctivitis, allergies, and other problems that the preservatives contained in ophthalmic solutions may cause to ocular surface homeostasis, there is increasing demand for ophthalmic solutions that contain little or no preservatives [22]. Actually, clinical efficacy and safety profiles of BAK-free prostaglandin analogues have been well-documented, and their reduced ocular side effects have been indicated [23-26].

Latanoprost ophthalmic solution $0.005 \%\lceil\mathrm{NP}\rfloor$ formulation without BAK is a commercially available latanoprost generic drug, approved and launched in Japan in November 2010. Latanoprost NP is packaged in a no-preservative multi-dose container (NP container) which allows it to be BAK free. The NP container is constructed from 5 basic parts: a cap, nozzle, housing, inside cork and container in Figure 4(a). The NP container enables the prevention of secondary contamination with two kinds of internally-mounted filters on Figure 4(b). Liquid in the container is out-flowed aseptically through a hydrophilic filter by squeezing the bottle. After

Table 2. $90 \%$ confidence interval for $\Delta \mathrm{C}_{\operatorname{max0} 0-24 \mathrm{hr}}$ and $\triangle \mathrm{AUC}_{0-24 \mathrm{hr}}$ values (log transformed).

\begin{tabular}{cccc}
\hline Parameters & Latanoprost & $\mathrm{NP}$ & $\begin{array}{c}90 \% \text { confidence } \\
\text { interval }\end{array}$ \\
\hline $\begin{array}{c}\Delta \mathrm{C}_{\mathrm{max} 0-24 \mathrm{~h}} \\
(\mathrm{mmHg})\end{array}$ & $3.08 \pm 1.38$ & $3.25 \pm 1.06$ & $81.22 \%-116.85 \%$ \\
$\begin{array}{c}\Delta \mathrm{AUC} \\
(\mathrm{mmHg} \cdot \mathrm{hr})\end{array}$ & $39.67 \pm 26.83$ & $43.00 \pm 19.77$ & $91.60 \%-106.27 \%$ \\
\hline
\end{tabular}




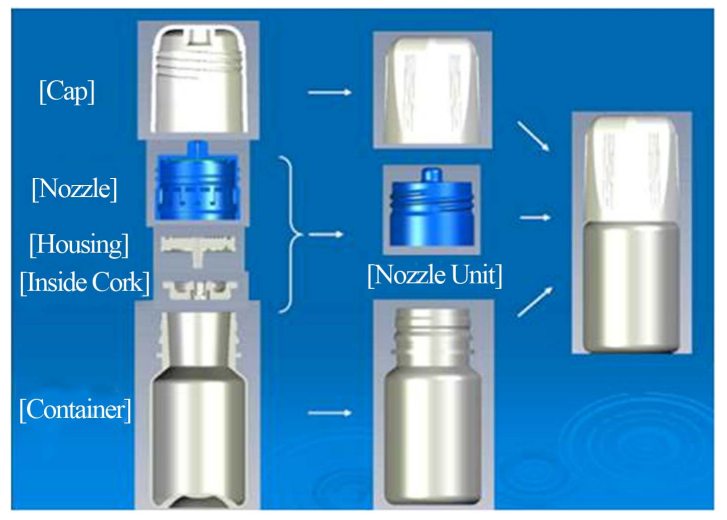

(a)

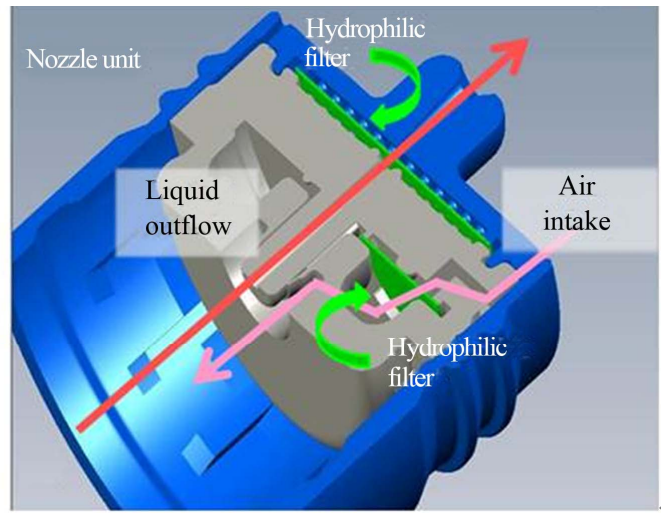

(b)

Figure 4. None-preservative multi-dose container (NP container); (a) shows structural attribute of NP container. The NP container consists of 5 parts, cap, nozzle, housing and container; (b) is concept illustration of characteristics of Nozzle Unit.

administration of the ophthalmic solution, the NP container takes in air through a hydrophobic filter. The NP container is designed not to absorb the liquid like tears through the liquid outflow route. A valve on the inside cork prevents any of the drug solution from flowing backwards and making contact with the hydrophilic filter. The NP container is small in size and portable similar to most conventional containers, and is easy to use.

The results of the in vitro cytotoxicity study indicated that NP formulation is safer than latanoprost with BAK on the ocular surface. According to many studies [27-30], cytotoxicity of antiglaucoma drugs was thought to depend on BAK. NP formulation does not include BAK and our result supports the results of these reports.

The results of the in vitro pharmacology study, NP had a protective effect against oxidative stress in HCECs while commercially available latanoprost with BAK did not. Some previous studies have indicated that prostaglandin analogues have cytoprotective and antioxidative effects in vitro $[31,32]$ and these results corresponded with our result. Although the cause of the effect of commercially available latanoprost with BAK was not clear, it was thought that the cytotoxic effect of BAK may counteract the protective effect of the commercially available latanoprost with BAK.

In pharmacodynamics and the measurement of latanoprost free acid in aqueous humor study, normal male cynomolgus monkeys were used to estimate the comparative effects of repeat instillation on IOP and on transcorneal drug delivery of latanoprost with BAK and NP. There was no significant difference between the mean latanoprost free acid concentration values of latanoprost with BAK and NP, but latanoprost free acid concentration after application of NP tended to be lower than latanoprost free acid concentration after application of latanoprost with BAK. In addition, the IOP reduction effect of NP was greater than that of latanoprost with
BAK throughout instilled duration. The results of the values of latanoprost free acid in aqueous humor and maximal IOP reduction effects of latanoprost with BAK and NP indicate that a high concentration of latanoprost free acid in aqueous humor is not always necessary to strongly lower IOP in Figure 5.

The bioequivalence study in healthy Japanese volunteers demonstrated that NP was an acceptable bioequivalent of latanoprost with BAK, because the $90 \%$-CIs of $\Delta \mathrm{C}_{\operatorname{max2} 2-24 \mathrm{~h}}$ and $\Delta \mathrm{AUC}_{2-24 \mathrm{~h}}$ laid within an acceptance range of $80 \%-125 \%$. The human results from the bioequivalence study were consistent with those of the monkey study, indicating that the effect of NP on IOP was equivalent to that of latanoprost with BAK, even if corneal transparency of latanoprost free acid with administration of NP tended to be lower than corneal transparency of latanoprost free acid with administration of latanoprost with BAK in animals. Moreover, it has previously been reported that another latanoprost formulation without BAK had strong IOP-lowering effects and maintained a hypotensive effect 3 months after a switch from latanoprost with BAK in patients with normal-tension glaucoma [33]. This, along with our results, suggested that latanoprost formulations without BAK were just as effective as latanoprost formulations with BAK.

In conclusion, we found that NP demonstrates low toxicity towards ocular surfaces. Repeat instillation of $\mathrm{NP}$ was effective and tolerated just as well as comercially available latanoprost with BAK and high concentration of latanoprost free acid in aqueous humor might be not necessary to strongly reduce IOP in non-human primates. Moreover, statistical analyses of primary parameters provided evidence for the therapeutic equivalence of the two latanoprost formulations: the $90 \%$-CIs for the comparison between latanoprost with BAK and NP were within the predefined acceptance range of $80 \%-120 \%$ for both, $\Delta \mathrm{C}_{\max 2-24 \mathrm{~h}}$ and $\Delta \mathrm{AUC}_{2-24 \mathrm{~h}}$. These results indi- 


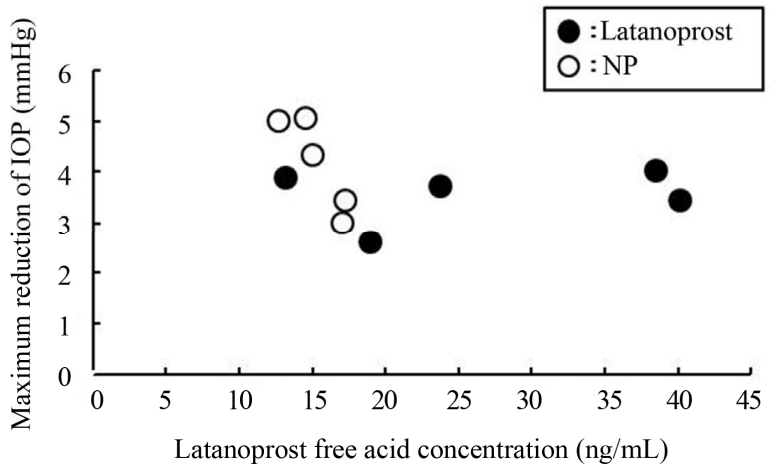

Figure 5. Relationship between maximal reduction IOP and latanoprost free acid concentration in aqueous humor in normotensive cynomolgus monkeys. Each dot represents individual data.

cated that NP was effective and might be more likely to preserve ocular surface health than latanoprost with BAK.

\section{REFERENCES}

[1] A. Iwase, Y. Suzuki, M. Araie, T. Yamamoto, H. Abe, S. Shirato, Y. Kuwayama, H. K. Mishima, H. Shimizu, G. Tomita, Y. Inoue and Y. Kitazawa, "The Prevalence of Primary Open-Angle Glaucoma in Japanese: The Tajimi Study," Ophthalmology, Vol. 111, No. 9, 2004, pp. 16411648.

[2] Y Hotehama, H. K. Mishima, Y. Kitazawa and K. Masuda, "Ocular Hypotensive Effect of PhXA41 in Patients with Ocular Hypertension or Primary Open-Angle Glaucoma," Japanese of Journal Ophthalmology, Vol. 37, No. 3, 1993, pp. 270-274.

[3] M. Diestelhorst, G. K. Krieglstein, M. Lusky and S. Nagasubramanian, "Clinical Dose-Regimen Studies with Latanoprost, a New Ocular Hypotensive PGF2 Alpha Analogue," Survey of Ophthalmology, Vol. 41, Suppl. 2, 1997, pp. S77-S81. doi:10.1016/S0039-6257(97)80011-2

[4] K. Kashiwagi, T. Tsumura and S. Tsukahara, "LongTerm Effects of Latanoprost Monotherapy on Intraocular Pressure in Japanese Glaucoma Patients," Journal of Glaucoma, Vol. 17, No. 8, 2008, pp. 662-666. doi:10.1097/IJG.0b013e318166656d

[5] K. Inoue, K. Okugawa, S. Kato, Y. Inoue, G. Tomita, T. Oshika and S. Amano, "Ocular Factors Relevant to AntiGlaucomatous Eyedrop-Related Keratoepitheliopathy," Journal of Glaucoma, Vol. 12, No. 6, 2003, pp. 480-485. doi:10.1097/00061198-200312000-00007

[6] P. Baffa Ldo, J. R. Ricardo, A. C. Dias, C. M. Módulo, A. M. Braz, J. S. Paula, L. Rodrigues Mde and E. M. Roch, "Tear Film and Ocular Surface Alterations in Chronic Users of Antiglaucoma Medications," Arquivos Brasileiros de Oftalmologia, Vol. 71, No. 1, 2008, pp. 18-21. doi:10.1590/S0004-27492008000100004

[7] N. Jaenen, C. Baudouin, P. Pouliquen, G. Manni, A. Figueiredo and T. Zeyen, "Ocular Symptoms and Signs with Preserved and Preservative-Free Glaucoma Medications,"
European Journal of Ophthalmology, Vol. 17, No. 3, 2007, pp. 341-349.

[8] J. Sarkar, S. Chaudhary, A. Namavari, O. Ozturk, J. K. Chang, L. Yco, S. Sonawane, V. Khanolkar, J. Hallak and S. Jain, "Corneal Neurotoxicity Due to Topical Benzalkonium Chloride," Investigative of Ophthalmology and Visual Science, Vol. 53, No. 4, 2012, pp. 1792-1802. doi:10.1167/iovs.11-8775

[9] G. A. Georgiev, N. Yokoi, K. Koev, E. Kutsarova, S. Ivanova, A. Kyumurkov, A. Jordanova, R. Krastev and Z. Lalchev, "Surface Chemistry Study of the Interactions of Benzalkonium Chloride with Films of Meibum, Corneal Cells Lipids, and Whole Tears," Investigative of Ophthalmology and Visual Science, Vol. 52, No. 7, 2011, 46454654. doi:10.1167/iovs.10-6271

[10] S. P. Epstein, M. Ahdoot, E. Marcus and P. A. Asbell, "Comparative Toxicity of Preservatives on Immortalized Corneal and Conjunctival Epithelial Cells," Journal of Ocular Pharmacology and Therapeutics, Vol. 25, No. 2, 2009, pp. 113-119. doi:10.1089/jop.2008.0098

[11] A. M. Stevens, P. A. Kestelyn, D. De Bacquer and P. G. Kestelyn, "Benzalkonium Chloride Induces Anterior Chamber Inflammation in Previously Untreated Patients with Ocular Hypertension as Measured by Flare Meter: A Randomized Clinical Trial," Acta Ophthalmologica, Vol. 90, No. 3, 2012, pp. e221-e224. doi:10.1111/j.1755-3768.2011.02338.x

[12] D. A. Ammar and M. Y. Kahook, "Effects of Benzalkonium Chloride- or Polyquad-Preserved Fixed Combination Glaucoma Medications on Human Trabecular Meshwork Cells," Molecular Vision, Vol. 17, 2011, pp. 18061813.

[13] K. Miyake, N. Ibaraki, Y. Goto, S. Oogiya, J. Ishigaki, I. Ota and S. Miyake, "ESCRS Binkhorst Lecture 2002: Pseudophakic Preservative Maculopathy," Journal of Cataract and Refractive Surgery, Vol. 29, No. 9, 2003, pp. 1800-1810. doi:10.1016/S0886-3350(03)00560-1

[14] R. Hackett and T. McDonald, "Eye Irritation," In: F. Marzulli and H. Maibach, Eds., Advances in Modern Toxicology: Dermatoxicology, Hemisphere Publishing Corporation, Washington DC, 1991, pp. 749-815.

[15] Guideline for Bioequivalence Studies of Generic Products, 22 December 1997.

[16] K. Kashiwagi, "Changes in Trend of Newly Prescribed Anti-Glaucoma Medications in Recent Nine Years in a Japanese Local Community," The Open Ophthalmology Journal, Vol. 28, No. 4, 2010, pp. 7-11. doi:10.2174/1874364101004010007

[17] E. P. O'Donoghue, “A Comparison of Latanoprost and Dorzolamide in Patients with Glaucoma and Ocular Hypertension: A 3 Month, Randomised Study. Ireland Latanoprost Study Group," British Journal of Ophthalmology, Vol. 84, No. 6, 2000, pp. 579-582. doi:10.1136/bjo.84.6.579

[18] W. Y. Zhang, A. L. Po, H. S. Dua and A. Azuara-Blanco, "Meta-Analysis of Randomised Controlled Trials Comparing Latanoprost with Timolol in the Treatment of Patients with Open Angle Glaucoma or Ocular Hyperten- 
sion," British Journal of Ophthalmology, Vol. 85, No. 8, 2001, pp. 983-990. doi:10.1136/bjo.85.8.983

[19] H. Tsukamoto, H. K. Mishima, Y. Kitazawa, M. Araie, H. Abe and A. Negi (Glaucoma Study Group), "A Comparative Clinical Study of Latanoprost and Isopropyl Unoprostone in Japanese Patients with Primary Open-Angle Glaucoma and Ocular Hypertension," Journal of Glaucoma, Vol. 11, No. 6, 2002, pp. 497-501. doi:10.1097/00061198-200212000-00008

[20] P. T. Che, T. Aung, M. V. Aquino and P. Rojanapongpun (EXACT Study Group), "Intraocular Pressure-Reducing Effects and Safety of Latanoprost versus Timolol in Patients with Chronic Angle-Closure Glaucoma," Ophthalmology, Vol. 111, No. 3, 2004, pp. 427-434. doi:10.1016/j.ophtha.2003.06.007

[21] P. Denis, C. Baudouin, A. Bron, J. P. Nordmann, J. P. Renar, J. F. Rouland, E. Sellem and M. Amrane, "FirstLine Latanoprost Therapy in Ocular Hypertension or Open-Angle Glaucoma Patients: A 3-Month Efficacy Analysis Stratified by Initial Intraocular Pressure," BMC Ophthalmology, Vol. 10, 2010, p. 4. doi:10.1186/1471-2415-10-4

[22] C. Baudouin, A. Labbé, H. Liang, A. Pauly and F. Brignole-Baudouin, "Preservatives in Eyedrops: The Good, the Bad and the Ugly," Progress in Retinal and Eye Research, Vol. 29, No. 4, 2010, pp. 312-334. doi:10.1016/j.preteyeres.2010.03.001

[23] S. K. Mirza and S. M. Johnson, "Efficacy and Patient Tolerability of Travoprost BAK-Free Solution in Patients with Open-Angle Glaucoma and Ocular Hypertension," Clinical Ophthalmology, Vol. 4, 2010, pp. 877-888. doi:10.2147/OPTH.S6292

[24] G. Katz, C. L. Springs, E. R. Craven and M. MontecchiPalmer, "Ocular Surface Disease in Patients with Glaucoma or Ocular Hypertension Treated with Either BAKPreserved Latanoprost or BAK-Free Travoprost," Clinical Ophthalmology, Vol. 4, 2010, pp. 1253-1261. doi:10.2147/OPTH.S14113

[25] M. J. Miyashiro, S. C. Lo, J. A. Stewart and W. C. Stewart, "Efficacy, Safety, and Tolerability of Travoprost $0.004 \%$ BAK-Free versus Prior Treatment with Latanoprost $0.005 \%$ in Japanese Patients," Clinical Ophthalmology, Vol. 4, 2010, pp. 1355-1359. doi:10.2147/OPTH.S13460

[26] A. Hommer, "A Review of Preserved and PreservativeFree Prostaglandin Analogues for the Treatment of Open-
Angle Glaucoma and Ocular Hypertension," Drugs of Today (Barcelona), Vol. 46, No. 6, 2010, pp. 409-416. doi:10.1358/dot.2010.46.6.1482107

[27] C. Baudouin, L. Riancho, J. M. Warnet and F. Brignole, "In Vitro Studies of Antiglaucomatous Prostaglandin Analogues: Travoprost with and without Benzalkonium Chloride and Preserved Latanoprost," Investigative of Ophthalmology and Visual Science, Vol. 48, No. 9, 2007, pp. 4123-4128. doi:10.1167/iovs.07-0266

[28] M. Ayaki, A. Iwasawa and Y. Inoue, "Toxicity of Antiglaucoma Drugs with and without Benzalkonium Chloride to Cultured Human Corneal Endothelial Cells," Clinical Ophthalmology, Vol. 4, 2010, pp. 1217-1222. doi:10.2147/OPTH.S13708

[29] H. Liang, A. Pauly, L. Riancho, C. Baudouin and F. Brignole-Baudouin, "Toxicological Evaluation of PreservativeContaining and Preservative-Free Topical Prostaglandin Analogues on a Three-Dimensional-Reconstituted Corneal Epithelium System," British Journal of Ophthalmology, Vol. 95, No. 6, 2011, pp. 869-875. doi:10.1136/bjo.2010.189449

[30] S. Nakagawa, T. Usui, S. Yokoo, S. Omichi, M. Kimakura, Y. Mori, K. Miyata, M. Aihara, S. Amano and M. Araie, "Toxicity Evaluation of Antiglaucoma Drugs Using Stratified Human Cultivated Corneal Epithelial Sheets," Investigative of Ophthalmology and Visual Science, Vol. 53, No. 9, 2012, pp. 5154-5160. doi:10.1167/iovs.12-9685

[31] J. M. Guenoun, C. Baudouin, P. Rat, A. Pauly, J. M. Warnet and F. Brignole-Baudouin, "In Vitro Comparison of Cytoprotective and Antioxidative Effects of Latanoprost, Travoprost, and Bimatoprost on Conjunctiva-Derived Epithelial Cells," Investigative of Ophthalmology and Visual Science, Vol. 46, No. 12, 2005, pp. 4594-4549. doi:10.1167/iovs.05-0776

[32] A. L. Yu, R. Fuchshofer, A. Kampik and U. Welge-Lüssen, "Effects of Oxidative Stress in Trabecular Meshwork Cells Are Reduced by Prostaglandin Analogues," Investigative of Ophthalmology and Visual Science, Vol. 49, No. 11, 2008, pp. 4872-4880. doi:10.1167/iovs.07-0984

[33] K. Inoue, M. Masumoto, M. Wakakura and G. Tomita, "Ocular Hypotensive Effects and Safety Latanoprost without Benzalkonium," Journal of the Eye, Vol. 28, No. 11, 2011, pp. 1635-1639. 